\title{
Measurement, growth types and shrinkage of newly formed aerosol particles at an urban research platform
}

\author{
Imre Salma $^{1}$, Zoltán Németh ${ }^{1}$, Tamás Weidinger ${ }^{2}$, Boldizsár Kovács ${ }^{3}$, and Gergely Kristóf ${ }^{3}$ \\ ${ }^{1}$ Institute of Chemistry, Eötvös University, P.O. Box 32, 1518 Budapest, Hungary \\ ${ }^{2}$ Department of Meteorology, Eötvös University, P.O. Box 32, 1518 Budapest, Hungary \\ ${ }^{3}$ Department of Fluid Mechanics, Budapest University of Technology and Economics, \\ Bertalan L. u. 4-6., 1111 Budapest, Hungary \\ Correspondence to: Imre Salma (salma@chem.elte.hu)
}

Received: 18 March 2016 - Published in Atmos. Chem. Phys. Discuss.: 30 March 2016

Revised: 5 June 2016 - Accepted: 7 June 2016 - Published: 27 June 2016

\begin{abstract}
Budapest platform for Aerosol Research and Training (BpART) was created for advancing long-term online atmospheric measurements and intensive aerosol sample collection campaigns in Budapest. A joint study including atmospheric chemistry or physics, meteorology, and fluid dynamics on several-year-long data sets obtained at the platform confirmed that the location represents a well-mixed, average atmospheric environment for the city centre. The air streamlines indicated that the host and neighbouring buildings together with the natural orography play an important role in the near-field dispersion processes. Details and features of the airflow structure were derived, and they can be readily utilised for further interpretations. An experimental method to determine particle diffusion losses in the differential mobility particle sizer (DMPS) system of the BpART facility was proposed. It is based on CPC-CPC (condensation particle counter) and DMPS-CPC comparisons. Growth types of nucleated particles observed in 4 years of measurements were presented and discussed specifically for cities. Arch-shaped size distribution surface plots consisting of a growth phase followed by a shrinkage phase were characterised separately since they supply information on nucleated particles. They were observed in $4.5 \%$ of quantifiable nucleation events. The shrinkage phase took $1 \mathrm{~h} 34 \mathrm{~min}$ in general, and the mean shrinkage rate with standard deviation was $-3.8 \pm 1.0 \mathrm{~nm} \mathrm{~h}^{-1}$. The shrinkage of particles was mostly linked to changes in local atmospheric conditions, especially in global radiation and the gas-phase $\mathrm{H}_{2} \mathrm{SO}_{4}$ concentration through its proxy, or to atmospheric mixing in few cases. Some indirect results indicate that variations in the for-
\end{abstract}

mation and growth rates of nucleated particles during their atmospheric transport could be a driving force of shrinkage for particles of very small sizes and on specific occasions.

\section{Introduction and objectives}

It is increasingly recognised that atmospheric new particle formation (NPF) and consecutive particle growth events are also relevant in urban environments (e.g. Alam et al., 2003; Wehner et al., 2004; Borsós et al., 2012; Dall'Osto et al., 2013; Xiao et al., 2015). The events observed in cities can be interconnected to regional NPF (Salma et al., 2016), and, therefore, their occurrence frequency is also considerable (up to $25-30 \%$ on an annual scale), and the process often shows a remarkable seasonal dependency, with a monthly maximum of up to $60-75 \%$ in spring. New particle formation can increase the pre-existing particle number concentrations by a factor of 2-3 (Salma et al., 2011a). As an overall effect, daily mean relative contributions of NPF events to ultrafine (UF) particles (with diameter $d<100 \mathrm{~nm}$ ) for the near-city background, city centre and street canyon in a central European city in spring were estimated to be 42,30 and $23 \%$, respectively (Salma et al., 2014). These contributions are comparable to individual high-temperature emission sources such as automotive road traffic exhaust, common industrial combustion processes, cooking or residential heating at ordinary distances from the sources. This implies that NPF in urban environments can also affect public health. Inhalation of UF particles represents an excess health risk relative to coarse 
or fine particles of the same or similar chemical composition (Oberdörster et al., 2005). The specific effects are mainly associated with a large number of insoluble particles deposited in the respiratory system and their large total surface area (Braakhuis et al., 2014; Salma et al., 2015). Nucleated particles can also influence urban climate and heat islands in cities through affecting cloud formation and properties if they grow in size to cloud condensation nuclei (Merikanto et al., 2009; Kerminen et al., 2012).

New particle formation and the growth process is superimposed on high-temperature emission sources and atmospheric transformation processes, which can - in particular in cities - complicate the identification and classification of NPF events. Higher particle number concentration levels and their fluctuation, a larger number of relevant emission sources of UF particles, spatial distribution and temporal variability of the sources, and the fact that the Aitkenmode particles usually have larger abundance and smaller median diameters in cities than at remote sites are the main disturbance or complicating factors. Studies on NPF processes require long and continuous atmospheric measurements of aerosol, air pollutant gases and meteorological variables. Such experimental data sets have been becoming gradually available for some cities in the world. It is increasingly necessary that a systematic overview of the peculiarities and specific features of urban NPF considering several aspects is given. The major objectives of this paper are (1) to demonstrate and evaluate various types of NPF and growth processes specifically for cities, (2) to discuss the reasons for their occurrence, (3) to investigate and quantify the shrinkage of newly formed particles, (4) to interpret the effect of surrounding airflow patterns and spatial representativity of a new urban research facility, the Budapest platform for Aerosol Research and Training (BpART, URL: http://salma.web.elte.hu/BpArt), and (5) to introduce a correction method for particle diffusion losses in one of the major measuring systems for NPF studies.

\section{Methods}

\subsection{Measurement sites and time intervals}

The experimental work was realised in Budapest, Hungary. Most measurements were performed at the BpART facility (Fig. 1). The platform is to serve and advance the research of atmospheric aerosols through complex surfacebased and satellite-borne measurements, as well as to promote the education and training of $\mathrm{PhD}$ students and young researchers. It is based on an insulated metal container with internal dimensions of $2.00 \mathrm{~m}$ (width), $2.80 \mathrm{~m}$ (length) and $2.10 \mathrm{~m}$ (height) dedicated to on-line aerosol measurements and aerosol sample collections. It is located on the secondfloor balcony of the northern block of the Lágymányos Campus, Eötvös University. The WGS84 coordinates (altitude,
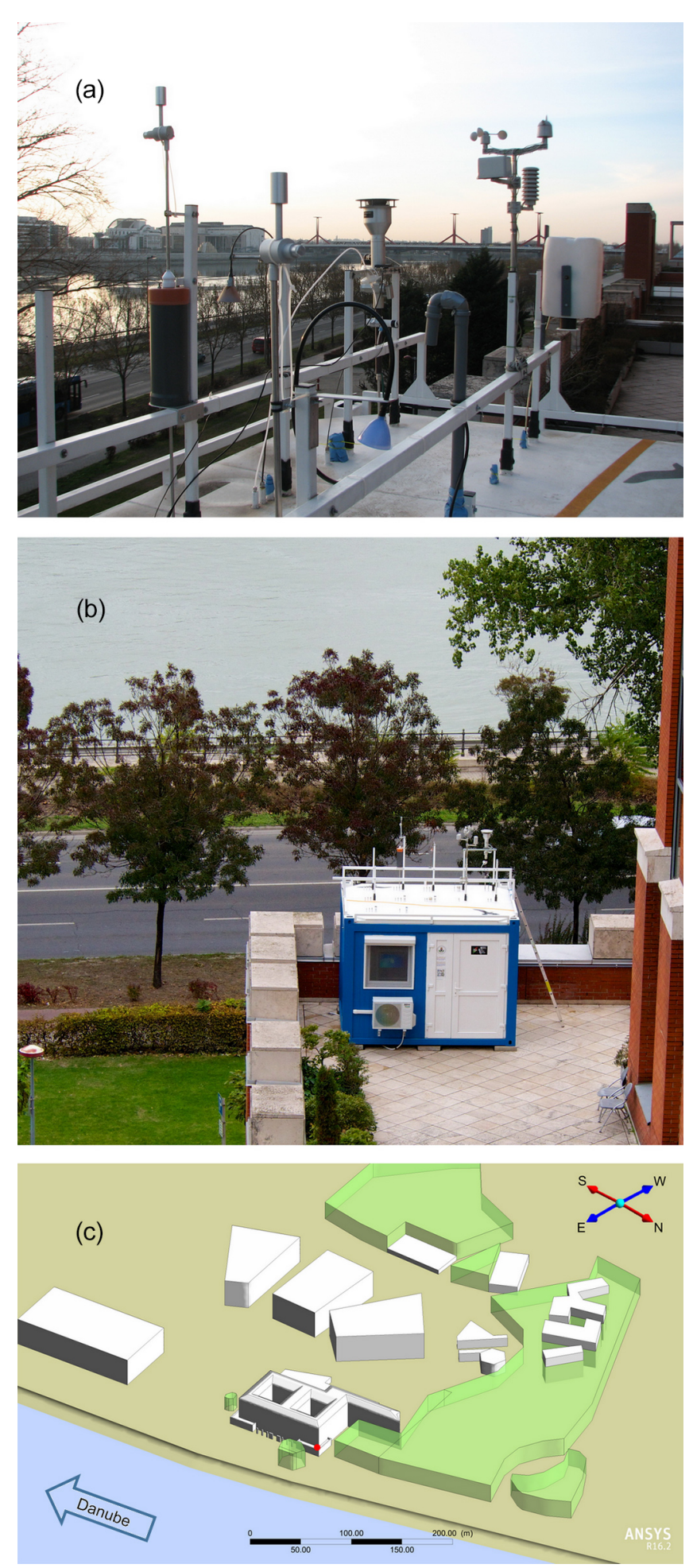

Figure 1. The superstructure (a) and close surroundings (b) of the BpART facility, together with a geometrical representation of the buildings and vegetation in a perspective view (c) utilised in the CFD modelling. The location of the platform is indicated by a red dot, and a compass rose is also shown in the lowest panel. 
longitude and height) of the NW upper corner of the container are $47^{\circ} 28^{\prime} 29.9^{\prime \prime} \mathrm{N}, 19^{\circ} 3^{\prime} 44.6^{\prime \prime} \mathrm{E}, 115.2 \mathrm{~m}$ above mean see level (a.s.1.). Its rooftop level is located at a height of $11.0 \mathrm{~m}$ above the street of the closest road. The distance of the container from the right bank of the River Danube is approximately $85 \mathrm{~m}$. The platform is equipped with an air conditioning facility, an electrical heating device, a heat barrier curtain at the door and a local area computer network. There are two independent lines for $230 \mathrm{~V}, 50 \mathrm{~Hz}, 12 \mathrm{~A}$ AC supply available for the instruments. The facility has been in continuous operation since November 2013. Experimental data obtained for two 1-year-long time intervals from 13 November 2013 to 12 November 2014 and from 13 November 2014 to 12 November 2015 were considered in the present study.

Sampling inlets and sensors are set up at heights between 80 and $150 \mathrm{~cm}$ above the rooftop level (Fig. 1a). The platform has several waterproof vertical inlets through the ceiling and some horizontal inlets with diameters of $64,10,8$ and $6 \mathrm{~mm}$. The aerosol instruments available include a filter dynamics measurement system tapered element oscillating microbalance (FDMS-TEOM 1400a, Rupprecht and Patashnick, USA), RT-OC/EC analyser (Sunset Laboratory, USA), differential mobility particle sizer (DMPS), stacked filter unit (SFU) sampler, micro-orifice uniform-deposit impactor (MOUDI), nano-MOUDI sampler (both MSP, USA) and high-volume dichotomous sampler (HiVol virtual impactor). The air pumped inside and processed by the instruments is forwarded to the outside via closed internal and external tubing to a distance from the receptor site of at least $3 \mathrm{~m}$ in the prevailing downwind direction. Meteorological data are available from both a regular urban climatological station (station number: 44505; name: Budapest Lagymanyos) of the Hungarian Meteorological Service operated at a height of $10 \mathrm{~m}$ above the roof level of the building (at a height of $39 \mathrm{~m}$ above the ground) at a distance of about $70 \mathrm{~m}$ from the BpART facility, and from a simpler on-site meteorological station. Aerosol optical thickness data can be retrieved via satellite receivers, which are located next to the regular meteorological station, from the Moderate Resolution Imaging Spectroradiometer (MODIS) on the Terra satellite.

Some additional experimental data utilised in the present paper were measured either in a near-city background on the western border of the city in a wooded area (latitude $47^{\circ} 30^{\prime} 1.4^{\prime \prime} \mathrm{N}$, longitude $18^{\circ} 57^{\prime} 46.3^{\prime \prime} \mathrm{E}$, altitude $478 \mathrm{~m}$ a.s.1.) from 18 January 2012 to 17 January 2013 or in a regular street canyon (Rákóczi Street, latitude $47^{\circ} 29^{\prime} 39.4^{\prime \prime} \mathrm{N}$, longitude $19^{\circ} 03^{\prime} 36.3^{\prime \prime} \mathrm{E}$, altitude $111 \mathrm{~m}$ a.s.l) situated in the city centre from 28 March to 31 May 2011 (Salma et al., 2014). The background is expected to represent the air masses entering the city since the prevailing wind direction is NW.

\subsection{Experimental methods}

The principal measuring system for the present study was a flow-switching type DMPS. Its main components are a radioactive bipolar charger, a Nafion semipermeable membrane dryer, a $28 \mathrm{~cm}$ long Hauke-type differential mobility analyser and a butanol-based condensation particle counter (TSI, model 3775, labelled as CPC1). Particles with an electrical mobility diameter from 6 to $1000 \mathrm{~nm}$ are recorded in their dry state (with a typical relative humidity $<30 \%$ ) in 30 channels. Sample flow is $2.0 \mathrm{~L} \mathrm{~min}^{-1}$ in high-flow mode and $0.3 \mathrm{~L} \mathrm{~min}^{-1}$ in low-flow mode, with sheath airflows 10 times larger than the sample flows. Time resolution of the measurement is approximately $8 \mathrm{~min}$. A weather shield and insect net were only attached to the inlet. The DMPS measurements were performed according to the international technical standards (Wiedensohler et al., 2012).

Particle transport losses in the DMPS system were determined in an intercomparison exercise by using an identical comparative CPC (labelled as CPC2, TSI, model 3775) for ambient air in two steps. First, the CPC ordinarily built in the DMPS system (CPC1) was compared to CPC2 to check their coherent functioning by operating them with an inlet sample flow of $0.3 \mathrm{~L} \mathrm{~min}^{-1}$ (low-flow mode) in parallel from 26 to 27 August 2015. A data averaging time interval of $5 \mathrm{~s}$ was chosen because the measuring time for a single channel of the DMPS is set to $5 \mathrm{~s}$. Circa $18 \times 10^{3}$ data pairs were obtained in this way. The operation of the CPCs is switched automatically and smoothly from live time-corrected singleparticle counting mode to photometric mode at a concentration around $5 \times 10^{4} \mathrm{~cm}^{-3}$ (Operation and Service Manual, 2007). As the second step of the exercise, the DMPS system and CPC2 were operated in parallel from 27 August to 3 September 2015. The individual concentration data measured by CPC2 (using an averaging time of $5 \mathrm{~s}$ ) were averaged for the actual measuring time intervals of the DMPS system (for cycle times of ca. $8 \mathrm{~min}$ ), while the concentrations obtained in the individual channels of the DMPS were summed up. Circa 1160 data pairs were derived in this way. Time intervals outside NPF were only considered in the later intercomparison step to minimise the effect of a non-identical lower diameter measuring limit of the DMPS $(6 \mathrm{~nm})$ and CPC2 (4 nm). The sampling lines for the CPCs and DMPS were prepared in an identical way and were set up at the BpART at a distance of $1 \mathrm{~m}$ from each other.

Standardised meteorological measurements of air temperature $(T)$, relative humidity $(\mathrm{RH})$, wind speed (WS), wind direction (WD) and precipitation (Prec) were recorded with a time resolution of $10 \mathrm{~min}$. Global radiation (GRad) was calculated from the measured meteorological data by the methodology of Holtslag and Van Ulden (Weidinger et al., 2008). Wind roses were based on the modern Beaufort scale of 0 (WS $\left.<0.3 \mathrm{~m} \mathrm{~s}^{-1}\right), 1\left(0.3-1.5 \mathrm{~m} \mathrm{~s}^{-1}\right), 2\left(1.6-3.3 \mathrm{~m} \mathrm{~s}^{-1}\right)$, $3\left(3.4-5.5 \mathrm{~m} \mathrm{~s}^{-1}\right), 4\left(5.6-7.9 \mathrm{~m} \mathrm{~s}^{-1}\right), 5\left(8.0-10.7 \mathrm{~m} \mathrm{~s}^{-1}\right), 6$ $\left(10.8-13.8 \mathrm{~m} \mathrm{~s}^{-1}\right)$ and $7\left(13.9-17.1 \mathrm{~m} \mathrm{~s}^{-1}\right)$. Concentrations 
of pollutant gases were obtained from the closest measurement station of the National Air Quality Network in Budapest (BP6) at a distance of $1.6 \mathrm{~km}$ from the urban site in the prevailing upwind direction. Concentrations of $\mathrm{SO}_{2}$ and $\mathrm{O}_{3}$ - considered here - were determined by UV fluorescence (Ysselbach 43C) and UV absorption (Ysselbach 49C, both Austria), respectively, with a time resolution of $1 \mathrm{~h}$. It is noted that the concentration of $\mathrm{SO}_{2}$ is ordinarily distributed without larger spatial differences within the city (Salma et al., 2001).

\subsection{Data evaluation and modelling}

The evaluation of the measured DMPS data was performed according to the procedure protocol recommended by Kulmala et al. (2012). Mathematically inverted size distributions were utilised for calculating particle number concentrations in the particle diameter ranges from 6 to $25 \mathrm{~nm}\left(N_{6-25}\right)$, from 6 to $100 \mathrm{~nm}\left(N_{6-100}\right)$, from 100 to $1000 \mathrm{~nm}\left(N_{100-1000}\right)$ and from 6 to $1000 \mathrm{~nm}(N)$. The individual size distributions were fitted by lognormal functions using the DoFit algorithm (Hussein et al., 2004) to determine modal parameters including the number of median diameters (NMDs). The individual concentration data were also utilised to generate particle number size distribution surface plots showing jointly the variation in particle diameter and particle number concentration density in time. The identification and classification of NPF processes was accomplished by using the algorithm of Dal Maso et al. (2005) on a day-to-day basis, with the following main classes: NPF event days, non-event days, days with undefined character and days with missing data for more than $4 \mathrm{~h}$ in the late morning. The frequency of events (for a month or a year) was determined as the ratio of the number of event days to the total number of relevant days. A subset of NPF events with uninterrupted evolution, which are called quantifiable (class-1A) events, were further distinguished to calculate their dynamic and timing properties. The growth rate (GR) of particles for a size interval of 6$25 \mathrm{~nm}$ was calculated by the log-normal distribution function method (Kulmala et al., 2012). The condensation sink (CS) for $\mathrm{H}_{2} \mathrm{SO}_{4}$ molecules onto the surface of existing dry aerosol particles was computed according to Dal Maso et al. (2005). The shrinkage rate (SR) of the nucleation-mode particles was derived as the slope of the fitted linear line of several NMD data in its time evolution plot, similarly to GRs. Gas-phase $\mathrm{H}_{2} \mathrm{SO}_{4}$ proxy values were calculated for GRad $>10 \mathrm{~W} \mathrm{~m}^{-2}$ according to Petäjä et al. (2009). The earliest estimated time of the beginning of a nucleation (time parameter $t_{1}$ ), the latest estimated time of the beginning of a nucleation (time parameter $t_{2}$ ) and the ending time of the particle growth process (time parameter $t_{\mathrm{e}}$ ) were determined for each quantifiable NPF event (Németh and Salma, 2014). The time parameter $t_{1}$ also includes the time shift that accounts for the particle growth from the stable neutral cluster mode at $(1.5 \pm 0.4) \mathrm{nm}$ (Kulmala et al., 2013) to the smallest detectable diameter limit of the DMPS systems $(6 \mathrm{~nm})$. Cur- rent local time $(\mathrm{CLT}=\mathrm{UTC}+1$ or daylight saving time of $\mathrm{UTC}+2$ ) was chosen as the timescale for the evaluations.

Airflow and dispersion of aerosol particles in the surroundings of the BpART research facility were investigated by using a three-dimensional computational fluid dynamics (CFD) model of the adjacent area in order to estimate the representativity of the results and conclusions obtained at the single measurement point. The model includes a detailed geometrical description of the host university building (where the platform is located) as well as simplified representations of the neighbouring buildings and vegetation within a $600 \mathrm{~m}$ radius area (Fig. 1c). In order to specify the boundary conditions, a $300 \mathrm{~m}$ wide relaxation zone was added to the periphery of the orographic model artificially, which equalises the terrain elevation height. The vertical profiles of velocity and turbulent quantities were specified at a cylindrically shaped lateral boundary. The domain height was set at $200 \mathrm{~m}$, and symmetrical boundary condition was used at the top of the domain. The numerical solution was developed in the ANSYSFLUENT solver (version 16.2) by using a realisable $k-\varepsilon$ turbulence model. A steady isothermal flow was assumed from eight different wind sectors on a $45^{\circ}$ angular raster. The vertical distribution of the inflow velocity and turbulence quantities were determined from a supplementary 2-D boundary layer model while obtaining the measured median WS in the eight wind sectors above the rooftop level. Both summer (vegetation with leaves) and winter (no vegetation) canopy conditions were taken into account. Porous resistance of the summer canopy for the vegetation was calculated from the leaf area index of the dominant flora as $5.3 \mathrm{~m}^{2} \mathrm{~m}^{-2}$ (Asner et al., 2003), while hydraulic resistance of the winter canopy was neglected. The observation volume element for the CFD modelling was set by the roof area of the BpART facility and by a height of $1 \mathrm{~m}$ above its rooftop level.

\section{Results}

Ranges and medians of the daily median particle number concentrations and UF particle contribution for central $\mathrm{Bu}-$ dapest are summarised in Table 1 for general orientation.

\subsection{Correction of transport losses}

Evaluation of the concentration data measured by CPC1 (ordinarily built into the DMPS system) and CPC2 (comparative instrument) is shown in Fig. 2. The agreement between the two CPCs near and above the limiting range between the single-particle counting mode and photometric mode is not sufficient. Both the scatter plot and concentration ratios show systematic deviations. This is most likely caused by differences in the live time correction at high counting rates and in the actual transition ranges between the operating modes for the two instruments, which are based on the manufacturer's calibration (Hermann et al., 2007). Fortunately, such high 
Table 1. Ranges and medians of daily total particle number concentrations $(N)$ and mean contributions of ultrafine (UF) particles to $N$ with standard deviations (SD) in central Budapest for 1-year-long intervals in 2008-2009, 2013-2014 and 2014-2015.

\begin{tabular}{lrrr}
\hline $\begin{array}{l}\text { Time } \\
\text { interval }\end{array}$ & $\begin{array}{r}\text { Range } \\
\left(\times 10^{3} \mathrm{~cm}^{-3}\right)\end{array}$ & $\begin{array}{r}\text { Median } N \\
\left(\times 10^{3} \mathrm{~cm}^{-3}\right)\end{array}$ & $\begin{array}{r}\text { Mean UF } / N \\
\pm \text { SD }(\%)\end{array}$ \\
\hline $2008-2009$ & $3.8-29$ & 11.8 & $79 \pm 6$ \\
$2013-2014$ & $2.8-23$ & 9.7 & $75 \pm 7$ \\
$2014-2015$ & $1.91-22$ & 9.3 & $75 \pm 8$ \\
\hline
\end{tabular}

concentrations do not occur when the CPC measures sizeseparated particle fractions in the channels of the DMPS system (see later). Considering the data below $3.0 \times 10^{4} \mathrm{~cm}^{-3}$, the slope of the regression line for the two CPCs was 1.034 and the mean concentration ratio with its standard deviation is $1.11 \pm 0.12$. The latter quantification seems to be in accordance with the nominal specification of CPCs, which means an agreement better than $\pm 10 \%$ between two instruments operating in the single-particle counting mode with a data averaging interval of $>30 \mathrm{~s}$. (For the photometric mode, the nominal agreement is $\pm 20 \%$.) There was no systematic deviation in the ratios with a concentration under $3.0 \times 10^{4} \mathrm{~cm}^{-1}$. The individual ratios, however, showed better agreement for night-time (slowly changing) values than for daytime (more dynamic) concentrations. For the time interval from 23:00 to 04:00 CLT, the coefficient of determination increased to $R^{2}=0.997$, the mean concentration ratio and its standard deviation decreased to $1.03 \pm 0.02$, and the slope and intercept of the regression line were 1.006 and $274 \mathrm{~cm}^{-1}$, respectively. In order to quantify the time response of the CPCs, an identical high-efficiency particulate-free air filter (HEPA filter capsule, Pall, USA) was adjusted to them in a stepwise manner. Temporal variation of the measured concentrations in this time interval is shown in Fig. 3. It can be seen that $\mathrm{CPC} 1$ reacted faster to the concentration decrease than $\mathrm{CPC} 2$ (although both satisfied the certified response time of $5 \mathrm{~s}$ to $95 \%$ of concentration step change). For CPC2, there was a fall of 4 orders of magnitude, which was followed by a slower decrease. The latter change could be expressed by a relaxation time of $1.6 \mathrm{~min}$. It is concluded that the difference of the timing properties of the CPCs can contribute to the moderate differences in the measured concentrations between the two CPCs. The difference can likely be decreased by a thorough renewed and updated calibration of the CPCs by the manufacturer.

Evaluation of the data obtained from the DMPS system and CPC2 operated in parallel is shown in Fig. 4. It is worth noting that no individually measured DMPS concentration data (in a channel) was larger than $1.0 \times 10^{4} \mathrm{~cm}^{-3}$ despite the fact that the comparison exercise was performed mostly under anticyclonic weather conditions, which are usually associated with more polluted air. It can be seen in Fig. 4

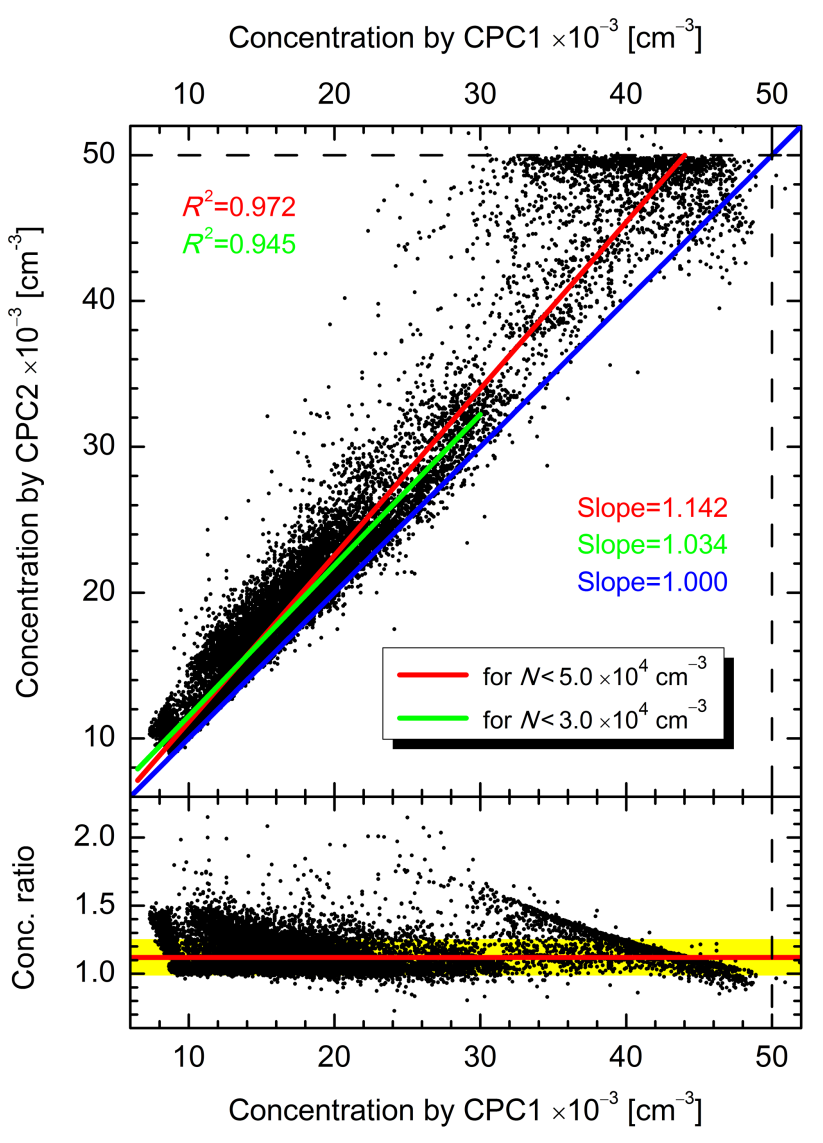

Figure 2. Scatter plot and CPC 2 / CPC1 concentration ratios for the data obtained by two identical CPCs. In the upper panel, the coefficients of determination of the data pairs $\left(R^{2}\right)$, the regression lines and their slopes are shown for concentrations $N<5.0 \times 10^{4}$ and $<3.0 \times 10^{4} \mathrm{~cm}^{-3}$ in the corresponding colours, together with the equality line. In the lower panel, the horizontal red line and yellow band indicate the mean concentration ratio and its standard deviation, respectively.

that the DMPS measures systematically smaller total concentrations than the CPC. This is due to larger transport losses of particles within the longer tubing and other parts of the DMPS system. The mean CPC / DMPS concentration ratio and its standard deviation were $1.26 \pm 0.18$, and the median ratio was 1.22 . The ratios did not indicate any tendency and resembled fluctuations both in time and with concentration. As a result of this intercomparison exercise, the median CPC / DMPS concentration ratio is adopted as a correction factor for the total particle number concentrations obtained by the DMPS system. It is worth noting that the intercept of the regression line and its standard deviation were $(-163 \pm 149) \mathrm{cm}^{-3}$, which indicates that the smallest reliably measurable total concentration with the DMPS is approximately $500 \mathrm{~cm}^{-3}$. The smallest total concentrations obtained in 3 years of operation in central Budapest were around $1000 \mathrm{~cm}^{-3}$, which confirms that the actual DMPS 


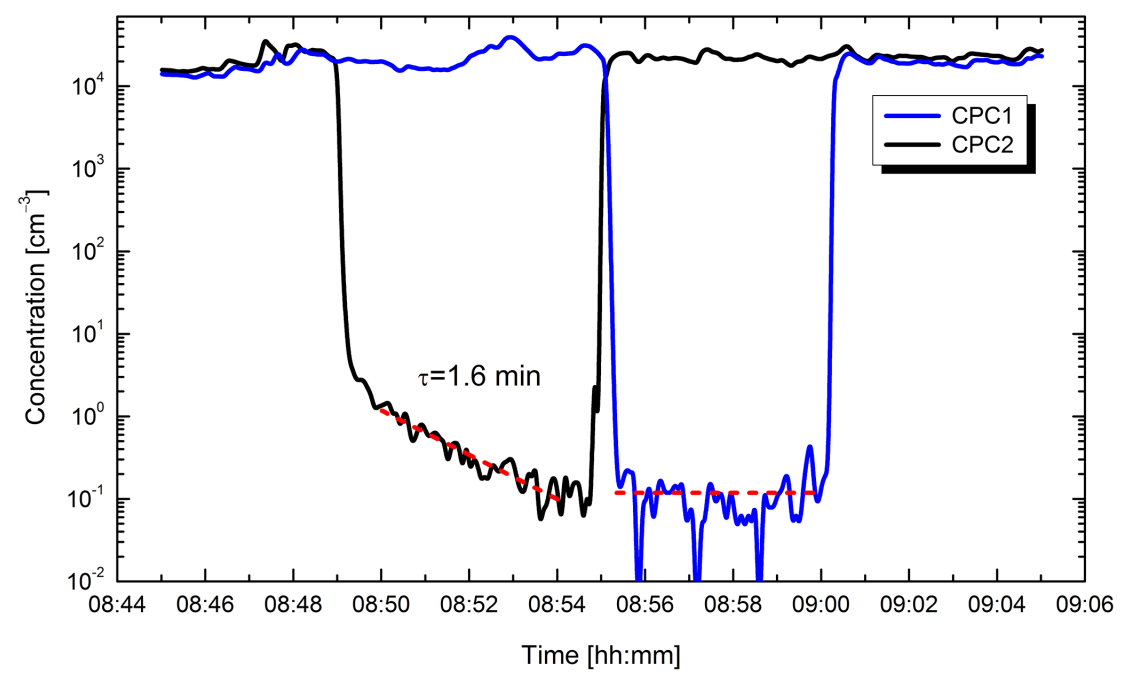

Figure 3. Temporal response of two identical CPCs to the concentration change caused by adjusting the same HEPA filter to them in a stepwise manner. The dashed lines show the fitted linear curves. Relaxation time $\tau$ of the slower CPC is also indicated.

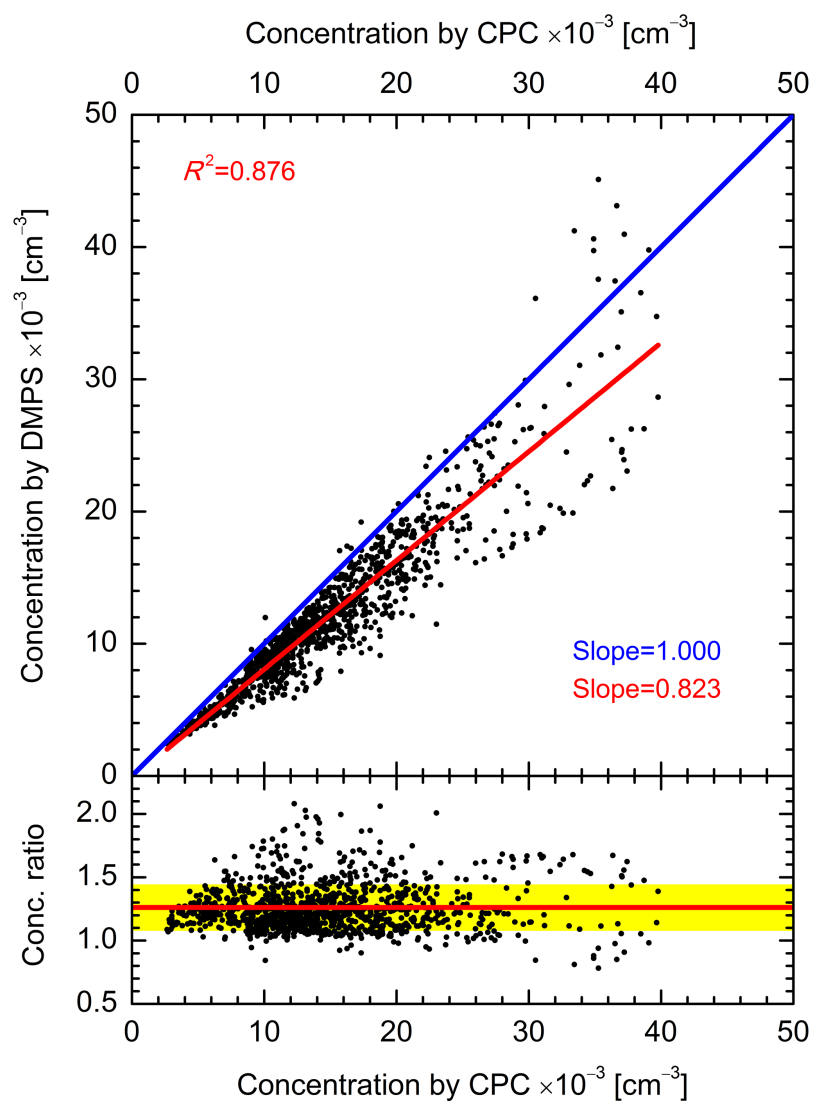

Figure 4. Scatter plot and CPC / DMPS concentration ratios for total particle number concentration data derived from the DMPS system and from an identical CPC. In the upper panel, the coefficient of determination of the data pairs $\left(R^{2}\right)$, the regression line and its slope are shown together with the equality line. In the lower panel, the horizontal red line and yellow band indicate the mean concentration ratio and its standard deviation, respectively. system is a capable and appropriate instrument under the atmospheric conditions encountered.

\subsection{Meteorological conditions and airflow structure around BpART}

Averages of some basic meteorological data inside and outside the BpART facility (based on ca. $50 \times 10^{3}$ measured data pairs each) are summarised in Table 2 for the 1-year-long time interval in 2013-2014. They demonstrate that the conditions inside the BpART can be well maintained (for $T$ and $\mathrm{RH}$ within $\pm 5^{\circ} \mathrm{C}$ and ca. $\pm 20 \%$, respectively) in ordinary operation for an annual run and that they enable high-quality experimental work at the platform. The conditions inside can be kept within even a narrower range for shorter time intervals. The outdoor mean $T$ is somewhat larger (by $1.3^{\circ} \mathrm{C}$ ), while the mean WS is somewhat smaller (by $0.7 \mathrm{~m} \mathrm{~s}^{-1}$ ) than for a climatological site in the city; this is most likely caused by local urban impacts, such as the heating and shadowing effects of the host and neighbouring buildings, and by the close vicinity of a large water reservoir (Danube). Wind roses derived for data sets obtained both above the rooftop level and on-site the BpART facility are shown in Fig. 5 for the 1-year-long time interval in 2013-2014. The data for the 1year-long time interval in 2014-2015 yielded similar results. It can be seen that the wind roses are rather different. The wind rose for the rooftop level shows the major WDs in $\mathrm{N}$ and NE due to the modifying effects of the natural orogeny (mainly Buda Mountains) and of the wind channel, which is often formed above the River Danube, on the prevailing synoptic wind (which is N-NW). At the same time, the wind rose for the on-site data shows three other major directions, namely $\mathrm{W}, \mathrm{SE}$ and $\mathrm{S}$. This latter property is largely governed by the effects of the actual urban canopy on the local urban 
Table 2. Ranges, medians and means with standard deviations for air temperature ( $T$ ), relative humidity (RH), wind speed (WS) and daily precipitation (Prec) inside and outside the BpART facility for 1-year-long ordinary operation in 2013-2014.

\begin{tabular}{|c|c|c|c|c|c|c|}
\hline \multirow{2}{*}{$\begin{array}{l}\text { Meteorological } \\
\text { variable/ } \\
\text { statistics }\end{array}$} & \multicolumn{2}{|c|}{ Inside } & \multicolumn{4}{|c|}{ Outside } \\
\hline & $\begin{array}{r}T \\
\left({ }^{\circ} \mathrm{C}\right)\end{array}$ & $\begin{array}{l}\text { RH } \\
(\%)\end{array}$ & $\begin{array}{r}T \\
\left({ }^{\circ} \mathrm{C}\right)\end{array}$ & $\begin{array}{l}\mathrm{RH} \\
(\%)\end{array}$ & $\begin{array}{r}\text { WS } \\
\left(\mathrm{ms}^{-1}\right)\end{array}$ & $\begin{array}{r}\text { Prec } \\
(\mathrm{mm})\end{array}$ \\
\hline 1st percentile & 14.5 & 21 & -2.6 & 37 & $<0.1$ & 0 \\
\hline Median & 18.2 & 39 & 14.8 & 79 & 1.4 & 0 \\
\hline 99th percentile & 23.1 & 66 & 33 & 99 & 6.1 & 30 \\
\hline Mean & 18.4 & 41 & 14.3 & 77 & 1.5 & 1.6 \\
\hline SD & 1.7 & 10 & 8.4 & 17 & 1.3 & 5.0 \\
\hline
\end{tabular}

airflow. The wind rose for the rooftop level, assuming that the major on-site WD of $\mathrm{W}$ and $\mathrm{WS}>0.3 \mathrm{~m} \mathrm{~s}^{-1}$, is also displayed in Fig. 5. It indicates that the arrival direction on a larger horizontal scale was obviously and almost exclusively N. Conditional wind roses for the other two major on-site directions of SE and $\mathrm{E}$ showed almost identical directions at the rooftop level, with somewhat more of an emphasis on the direction SE. The discrepancy between the wind roses at the two locations can be mainly explained by the effect of the actual urban construction. The interpretations based on the wind roses are further supported by airflow field modelling results (see below). Taking into account these relationships, the on-site meteorological station can be utilised as a reliable and prompt orientation in ordinary or extreme meteorological situations and for making immediate decisions during the experiments at the platform.

Streamlines (trajectories of massless particles) were traced back by using a reversed flow field from the observation volume element to a distance of $600 \mathrm{~m}$ in radius. The histogram of the starting point height for the eight major wind sectors is displayed in Fig. 6. It reveals that the effective sampling height changes with WD. The most probable height of origin was 3-8 $\mathrm{m}$ for most WDs (of N, NE, E, SE and NW). In the case of S, SW and W wind directions, however, when the observation volume element falls onto the lee side of the host building, most air parcels arrived from a height of 25$40 \mathrm{~m}$. This suggests that the airflow around the host building has a major impact on the sampling height. No substantial dependency on the canopy drag was found. Flow structure around the BpART facility for the eight major wind sectors in summer are shown in Fig. 7. The path lines indicate that the host and neighbouring buildings together with the natural orography play an important role in the near-field dispersion processes. Velocity distributions revealed that the vegetation causes a minor upward displacement of the streamlines, as expected, and that the near-ground velocity decreases. The airflows arriving from the directions N, NE, E and SE bring in air masses directly from further distances to the BpART facility. When the wind blows from S, SW, W or NW, the effects of eddies and turbulence at the platform cannot be neglected, and the on-site WSs are usually decreased and on-site WDs usually substantially modified. The details and features of the airflow structure should be taken into consideration when interpreting the horizontal extension of atmospheric processes and phenomena.

\subsection{Growth types of nucleated particles in cities}

Many NPF and consecutive particle growth processes were observed as banana-shaped plots (Fig. 8a), which indicate that the measurement site was often exposed to spatially homogenous air masses (Kivekäs et al., 2016). This shape was usually associated with regional nucleation phenomenon in the Carpathian Basin (Salma et al., 2016) and occurred under relatively clean atmospheric conditions. Some plots appeared with a narrow onset as an NPF burst. A few similar banana plots were also observed in rather polluted air. The basic preconditions of NPF events are realised by competing source and sink terms, and, therefore, NPF can occur even in polluted environments (with large condensation and scavenging sinks), provided that the source of condensable chemical species is large enough and other conditions are also favourable (Fig. 8b). Changes in the intensity of local emission sources can cause considerable fluctuations of the nucleation-mode NMD in the overlapping diameter range. A flow-mediated banana plot (Fig. 8c) was observed in the street canyon, which has one end at the bank of the River Danube, and the other end in the city. There are two essential horizontal airflows possible inside the canyon: either from or toward the river, which lead to rather diverse atmospheric conditions. In some cases, NPF events were clearly recognisable as banana plots for several hours when the wind blew from the river (bringing in cleaner and regionally more representative air masses), while the curve representing NPF disappeared when the airflow changed to the opposite direction (introducing more polluted air masses, in which there was no NPF and growth process going on or which inhibited the ongoing process).

Figure 9 shows NPF and particle growth events with multiple consecutive onsets. During the relevant time intervals, the properties which are related to NPF events (e.g. $N_{6-25}$ and gas-phase $\mathrm{H}_{2} \mathrm{SO}_{4}$ proxy) varied substantially and rapidly 

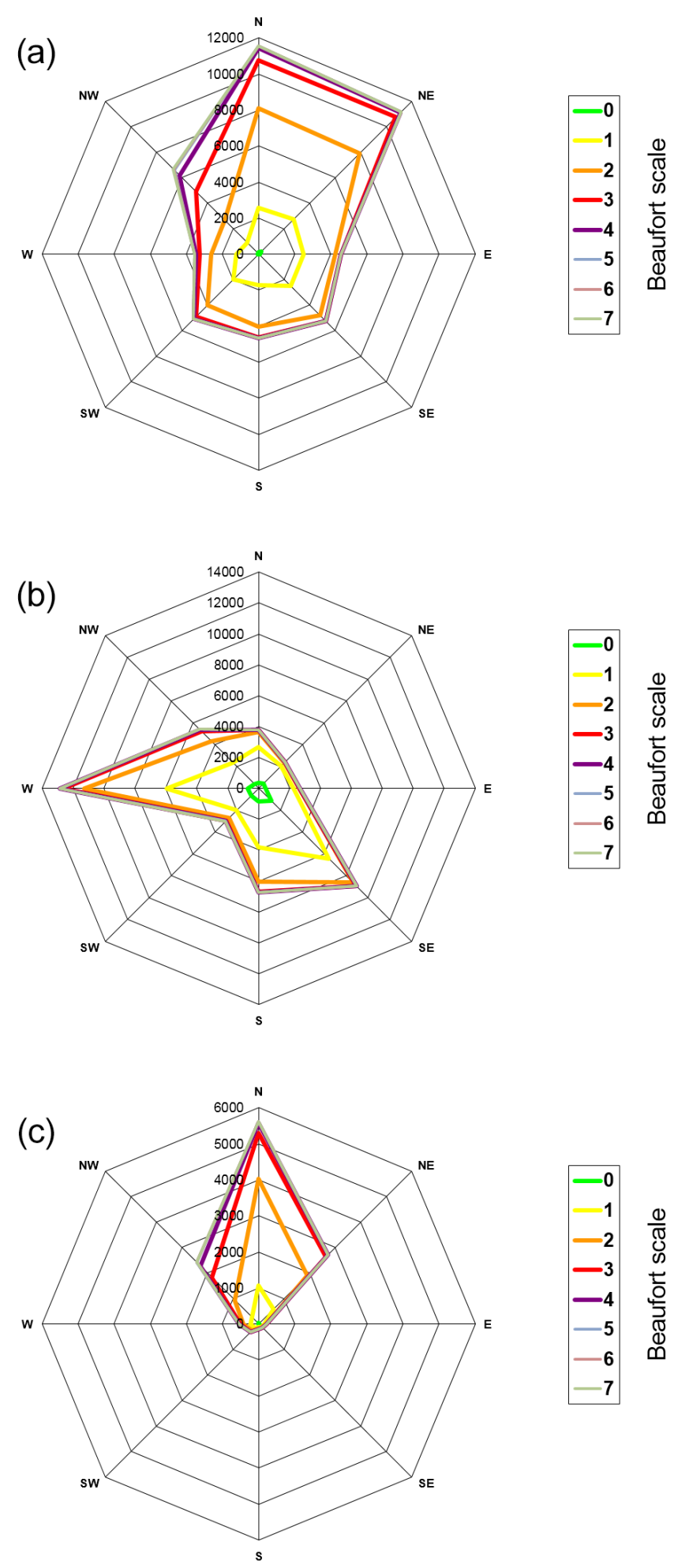

Figure 5. Wind roses based on the modern Beaufort scale for the data sets obtained above the rooftop level of the building (a), onsite the BpART facility (b), and for the data above the rooftop level on the condition that the WD on-site was W and its speed $>0.3 \mathrm{~m} \mathrm{~s}^{-1}$ (c). Figures on the vertical axis indicate the scale for the number of data belonging to each case. in time, while the concentration $N_{100-1000}$, which represents a larger spatial region, and the local WD, WS and GRad data, and the path of the air mass stayed largely constant (Salma et al., 2016). The first onset in Fig. 9a was associated with regional NPF, while the later onset occurred in a more polluted air, which was unambiguously of urban or local origin. This takes place, for instance, by mixing regional and urban air parcels that exhibit different properties, and it is mainly governed by local planetary boundary layer (PBL) dynamics and urban heat island effects (Kulmala et al., 2005; Hirsikko et al., 2013). An NPF with up to four onsets is shown in Fig. $9 \mathrm{~b}$ although none of them had developed into a banana plot. Multiple onsets, which occur close enough to each other in time, can result in overlap and can be a reasons for banana plots with a broad onset extending up to 4-6h (Fig. 9c). Determining the dynamic properties for such a shape could be challenging and associated with larger uncertainty.

Figure 10a shows an NPF with an uninterrupted particle growth which was limited in time. The duration of the growth phase can be variable. In some cases, the particle growth was followed by a reverse process, i.e. by a continuous decrease in nucleation-mode NMD as displayed in Fig. 10b. This combination results in an arch-shaped surface plot. In some cases, the nucleated particles shrank back to the smallest measurable diameter limit of $6 \mathrm{~nm}$ for the DMPS. The actual plot (Fig. 10b) was created in a blizzard when $\mathrm{SO}_{2}, \mathrm{WD}$ and trajectory path stayed mostly constant, daily median WS was $6 \mathrm{~m} \mathrm{~s}^{-1}$, and $T$ and RH decreased from a daily median of $3.0^{\circ} \mathrm{C}$ on the previous day to $-2.2^{\circ} \mathrm{C}$ on the day of the NPF and from 99 to $64 \%$, respectively. Another NPF occurred on the next day as well, which further supports the correct identification of the event. Arc-shaped surface plots contain information about the nucleated particles, and, therefore, they are further evaluated and discussed in Sect. 3.4.

Size distribution surface plots generated by NPF and growth events are usually superimposed on the effects of other urban emission sources and transformation processes. Some of them, such as vehicular road traffic, happen almost regularly since they often follow a diurnal activity pattern of inhabitants on workdays (Morawska et al., 2008; Salma et al., 2011b). Some other ordinary substantial emission sources, such as boat traffic on rivers in cities or diesel-driven single heavy-duty trucks or buses, cause sudden and considerable changes (red stripes) on surface plots in an irregular or occasional manner. Furthermore, number concentrations can be also modified very much or sometimes even in a determinative way by local meteorology and atmospheric mixing. A typical surface plot reflecting some of these effects is shown in Fig. 11a. Impacts of residential heating and combustion activities, mainly on winter evenings, can also add to the situation. Figure $11 \mathrm{~b}$ shows a surface plot for a very specific activity, namely extensive grass cutting in the park next to the BpART facility. It was likely generated by organic emissions from the lysed vegetation tissue combined with the exhaust emissions from the internal combustion engines, and it 


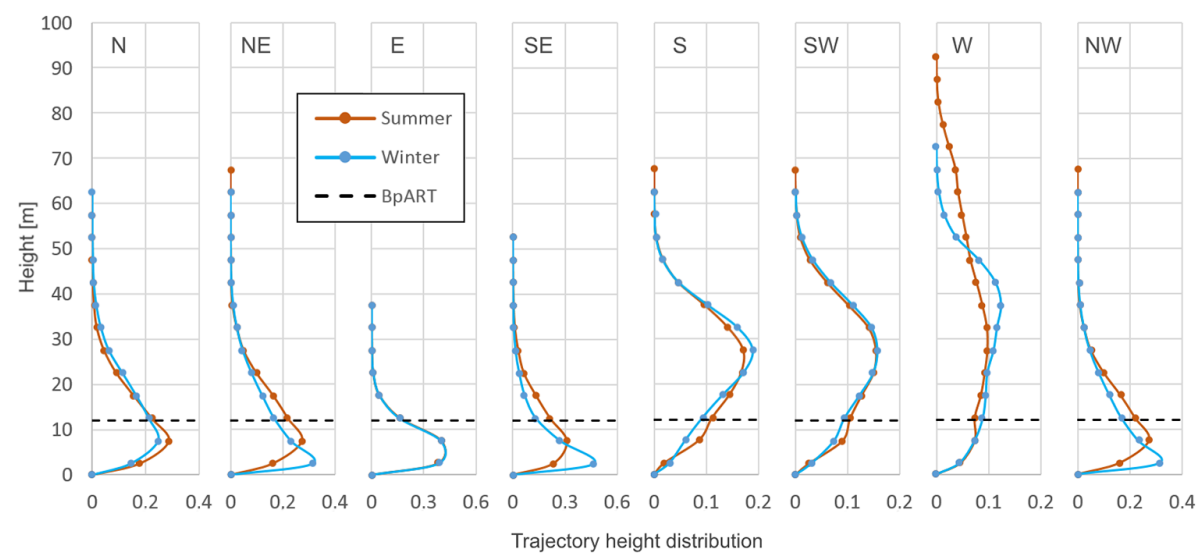

Figure 6. Histogram of the starting point height at a distance of $600 \mathrm{~m}$ from the BpART facility for the eight major wind sectors (N, NE, E, $\mathrm{SE}, \mathrm{S}, \mathrm{SW}, \mathrm{W}$ and NW) for summer (vegetation with leaves) and winter (no vegetation). The sampling height of the platform is indicated by dashed lines.

is expected to affect a very local area only and should not be classified as a NPF on a larger spatial scale. Even the particle growth observable around 21:00 UTC +2 cannot be considered an NPF event because it does not fulfil the requirements for NPF (Dal Maso et al., 2005) and because it also appeared after sunset. No nocturnal NPF events have been identified at all in Budapest since 2008. The growth was likely related to condensation on existing (Aitken-mode) particles, which was caused by changes in local meteorology (e.g. decrease in air temperature and/or air mixing) and atmospheric chemistry (Salma et al., 2011a). The example in Fig. 11 also points to the necessity of personal observations and their regular logging.

\subsection{Shrinkage of nucleated particles}

There were 178 quantifiable NPF and consecutive particle growth events identified in Budapest in 4 years. Of these, $4.5 \%$ (8 days) yielded well-developed uninterrupted archshaped surface plots. Most of them occurred in spring (50\%) and summer $(25 \%)$, although the number of cases was rather too limited to arrive at reliable conclusions. Arc-shaped surface plots were observed in NPF classes other than quantifiable events as well, but their rigorous evaluation was hindered by their ambiguous or interrupted growth or shrinkage phases and fluctuating data. The decreasing process of the Aitken-mode NMD was also detected on some nonnucleation days. The quantifiable events were only evaluated because they supply representative and reliable information on nucleated particles. The SR varied from -4.8 to $-2.3 \mathrm{~nm} \mathrm{~h}^{-1}$, with a mean and standard deviation of $(-3.8 \pm 1.0) \mathrm{nm} \mathrm{h}^{-1}$. The values are comparable to the data observed earlier (Yao et al., 2010; Young et al., 2013; Skrabalova et al., 2015). They are close in particular to the rates that represent shrinkage due to changing meteorological conditions (Cusack et al., 2013; Skrabalova et al., 2015), which is in line with our further evaluation (see later). The shrinkage driven by changes in the atmospheric mixing is usually more rapid (Yao et al., 2010). It is noted that the GR for the related NPF events varied from 3.4 to $6.1 \mathrm{~nm} \mathrm{~h}^{-1}$, with a mean and standard deviation of $(4.5 \pm 1.2) \mathrm{nm} \mathrm{h}^{-1}$. It was found earlier that particle GRs show seasonal dependency in the Carpathian Basin (Yli-Juuti et al., 2009; Salma et al., 2011a). A similar tendency for SRs could not be established so far due to the small number of arc-shaped surface plots.

The shrinkage of newly formed particles was earlier attributed to the evaporation of reversible condensed chemical species (for urban environments, see Yao et al., 2010, Backman et al., 2012, Young et al., 2013, Skrabalova et al., 2015; for a regional background, see Cusack et al., 2013). Its primary causes were explained either by changes in meteorological conditions or in atmospheric vertical mixing. They both lead to decreased atmospheric concentration of vapours below their supersaturation. Decrease in the nucleation-mode NMD due to coagulation and to the collapse of structured particles with void volume was not considered, especially since the latter possibility does not seem very realistic for nucleated particles. Recent studies reported that the particles which are grown after NPF contain organics (including carboxylic and hydroxyl acids and $\mathrm{N}$-containing organic compounds; Smith et al., 2008), nitrate, sulfate and ammonium ions as major chemical compounds (Bzdek et al., 2012). Some of them can be indeed semi-volatile. Another study (Kivekäs et al., 2016) concluded, however, that this explanation needs further elaboration since newly formed particles in their first stage are expected to consist of compounds having a low or extremely low vapour pressure (Ehn et al., 2014). Moreover, freshly nucleated particles with a median mobility diameter of ca. $20 \mathrm{~nm}$ collected on transmission electron microscopy (TEM) grids survived high-vacuum conditions in the TEM column, at least for a limited time (several tens of minutes; Németh et al., 2015). They evaporated when ex- 

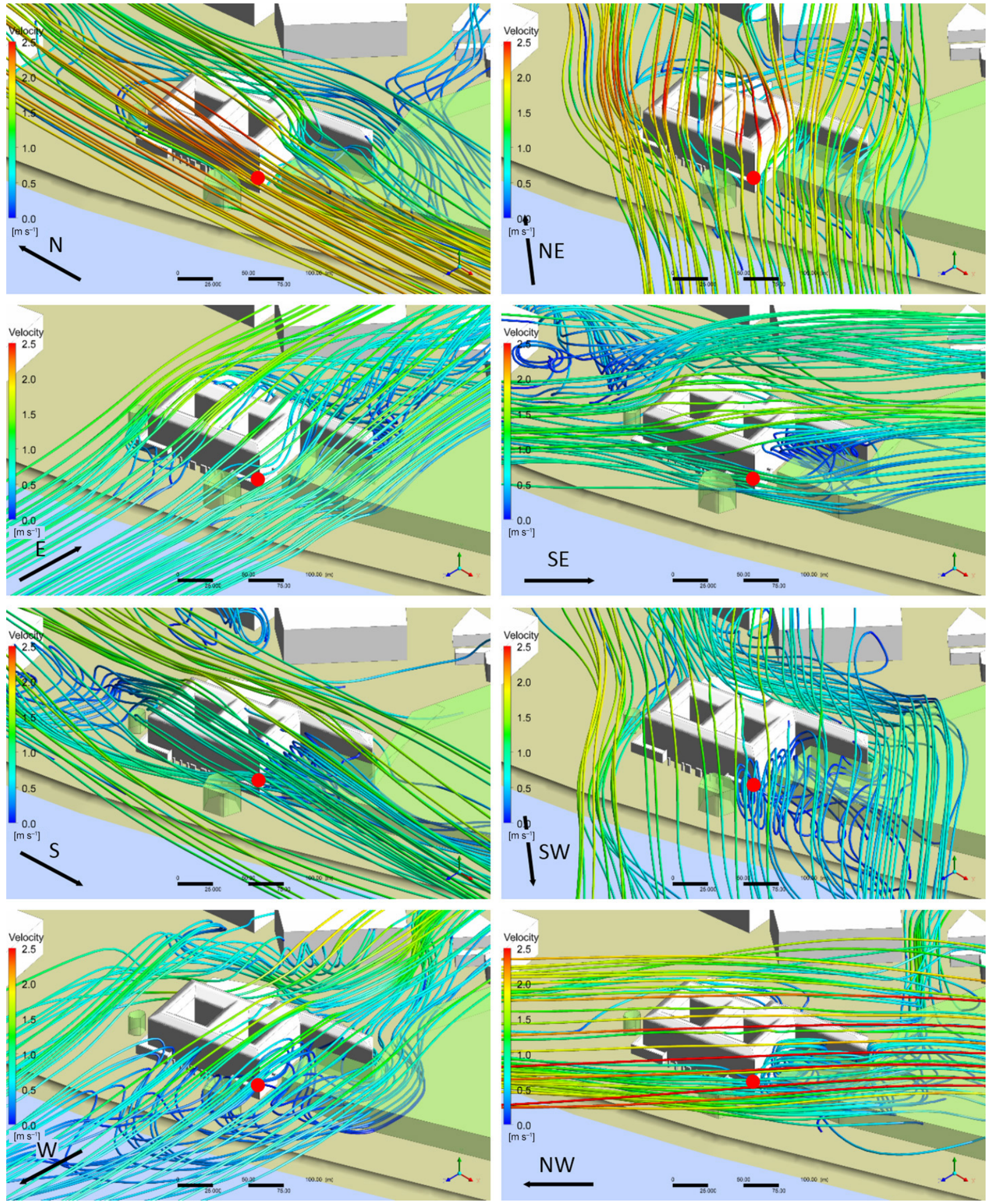

Figure 7. Path lines and speeds around the BpART facility for the eight major wind sectors (N, NE, E, SE, S, SW, W and NW) in summer (vegetation with leaves) in a perspective view. The wind directions are marked by an arrow and letters, and the location of the platform is indicated by a red dot in the panels. 
Table 3. Means and their mean relative change rates (in an hour expressed as percentage of the mean) separately for the growth $(G)$ and shrinkage $(S)$ phases of arch-shaped NPF processes, together with mean $G / S$ ratios of medians for the duration time, nucleation-mode particle number median diameter $\left(\mathrm{NMD}_{\text {nucl }}\right)$, particle number concentrations in various size fractions $\left(N_{6-25}, N_{6-100}, N_{100-1000}, N\right)$, condensation sink (CS), $\mathrm{SO}_{2}$ concentration, $\mathrm{O}_{3}$ concentration, gas-phase $\mathrm{H}_{2} \mathrm{SO}_{4}$ proxy value, global radiation (GRad), relative humidity $(\mathrm{RH})$, air temperature $(T)$ and wind speed (WS).

\begin{tabular}{|c|c|c|c|c|c|}
\hline \multirow[t]{2}{*}{ Variable } & \multicolumn{2}{|c|}{ Growth phase } & \multicolumn{2}{|c|}{ Shrinkage phase } & \multirow{2}{*}{$\begin{array}{r}\text { Mean } \\
G / S \text { ratio }\end{array}$} \\
\hline & Mean & Change & Mean & Change & \\
\hline Duration (hh:mm) & $1: 52$ & - & $1: 33$ & - & 1.2 \\
\hline $\mathrm{NMD}_{\text {nucl }}(\mathrm{nm})$ & 9.6 & 3 & 10.8 & -4 & 0.8 \\
\hline$N_{6-25}\left(\times 10^{3} \mathrm{~cm}^{-3}\right)$ & 7.6 & 68 & 6.5 & -47 & 1.6 \\
\hline$N_{6-100}\left(\times 10^{3} \mathrm{~cm}^{-3}\right)$ & 10.4 & 52 & 8.4 & -35 & 1.5 \\
\hline$N_{100-1000}\left(\times 10^{3} \mathrm{~cm}^{-3}\right)$ & 1.5 & n.r. & 1.2 & -4 & 1.5 \\
\hline$N\left(\times 10^{3} \mathrm{~cm}^{-3}\right)$ & 11.6 & 46 & 9.4 & -31 & 1.4 \\
\hline $\mathrm{CS}\left(\times 10^{3} \mathrm{~s}^{-1}\right)$ & 0.008 & 2 & 0.006 & -8 & 1.4 \\
\hline $\mathrm{SO}_{2}\left(\mu \mathrm{g} \mathrm{m}^{-3}\right)$ & 7.4 & -8 & 5.9 & 6 & - \\
\hline $\mathrm{O}_{3}\left(\mu \mathrm{g} \mathrm{m}^{-3}\right)$ & 57 & 22 & 75 & 3 & 0.6 \\
\hline Proxy $\left(\mu \mathrm{g} \mathrm{m}^{-5} \mathrm{~W} \mathrm{~s}\right)$ & 412 & 91 & 732 & -18 & 0.7 \\
\hline $\operatorname{GRad}\left(\mathrm{W} \mathrm{m}^{-2}\right)$ & 143 & 95 & 463 & -14 & 0.4 \\
\hline RH (\%) & 64 & -6 & 56 & 1.1 & 1.1 \\
\hline$T\left({ }^{\circ} \mathrm{C}\right)$ & 16 & 23 & 18 & -6 & 0.4 \\
\hline $\mathrm{WS}\left(\mathrm{m} \mathrm{s}^{-1}\right)$ & 1.4 & -4 & 1.3 & -3 & 1.1 \\
\hline
\end{tabular}

N.r.: not relevant (below $1 \%$ in absolute value).

posed to the electron beam. In addition, a simplified atmospheric transport model which considered temporal or spatial variations or both in the formation rate $(J)$ and GR during the transport could yield various shapes of surface plot for a fixed site including those showing a decrease in NMD and $N$ even if the local conditions did not vary.

In order to investigate the effect of the local meteorology and some air pollutants, two time intervals corresponding to the growth phase (increase of the nucleation mode NMD) and shrinkage phase (decrease in the nucleation mode NMD) of the arc-shaped plots were selected. The aerosol-related and meteorological properties characteristic of the growth and shrinkage conditions were averaged separately for these time intervals. The median values and change rates derived in this way were finally averaged for the identified 8 days together with the mean growth/shrinkage ratios (Table 3). It can be seen that evident particle growth and shrinkage happened for similar time intervals of ca. 1.5-2 h. Concentrations $N_{6-25}$, $N_{6-100}$ and $N$ increased substantially (by 45-70\%) during the growth phase, as expected, and they decreased in general by $30-50 \%$ during the shrinkage phase. As far as the individual cases are concerned, temporal variation of $N_{6-25}$ during the shrinkage phase decreased in almost all cases. In addition, the median $N_{6-25}$ concentration over the shrinkage phase was usually smaller than that over the growth phase. These can be explained by an increased coagulation sink for the shrinking particles. On a few (namely 2) days, an opposite tendency, i.e. increasing $N_{6-25}$ during the shrinkage phase, was observed. This could be explained by the con- tribution of urban emission sources to the upper end of the specified diameter interval (around $25 \mathrm{~nm}$ ), which could not be rejected on these specific days, or to the changes in local meteorology, which could modify atmospheric concentrations. Variations in $N_{100-1000}$ - representing a larger horizontal scale and background aerosol - over the growth and shrinkage phases were negligible. The concentration of $\mathrm{SO}_{2}$ precursor gas was also rather constant during both the growth and shrinkage phases, which suggests that $\mathrm{SO}_{2}$ is usually available in excess in the city (Salma et al., 2011a) and that the processes do not seem to be sensitive to $\mathrm{SO}_{2}$. A modest increase in CS observed during the growth phase can be explained by an increased surface area of the growing particles and particle number concentrations. In the shrinkage phase, CS was decreasing more rapidly than for the growth. The mean $T$ for the time interval of interest was between 16 and $18{ }^{\circ} \mathrm{C}$ for the present arc-shaped plots, but for several days it was well below $10^{\circ} \mathrm{C}$. The plot presented in Fig. $10 \mathrm{~b}$ even occurred at a daily median $T$ as low as $-2.2{ }^{\circ} \mathrm{C}$. This is an important extension to a previous conclusion (Skrabalova et al., 2015), according to which under ca. $12^{\circ} \mathrm{C}$ the evaporation of atmospherically relevant organics and $\mathrm{NH}_{4} \mathrm{NO}_{3}$ is significantly hindered. In the present case, other mechanisms, for instance sudden changes in atmospheric mixing or, more importantly, variations in $J$ and GR values during atmospheric transport should be considered. In addition, it is noted that there were no substantial changes in $T$ and $\mathrm{RH}$ between the growth and shrinkage phases, which implies that thermal evaporation or fragmentation of or water 

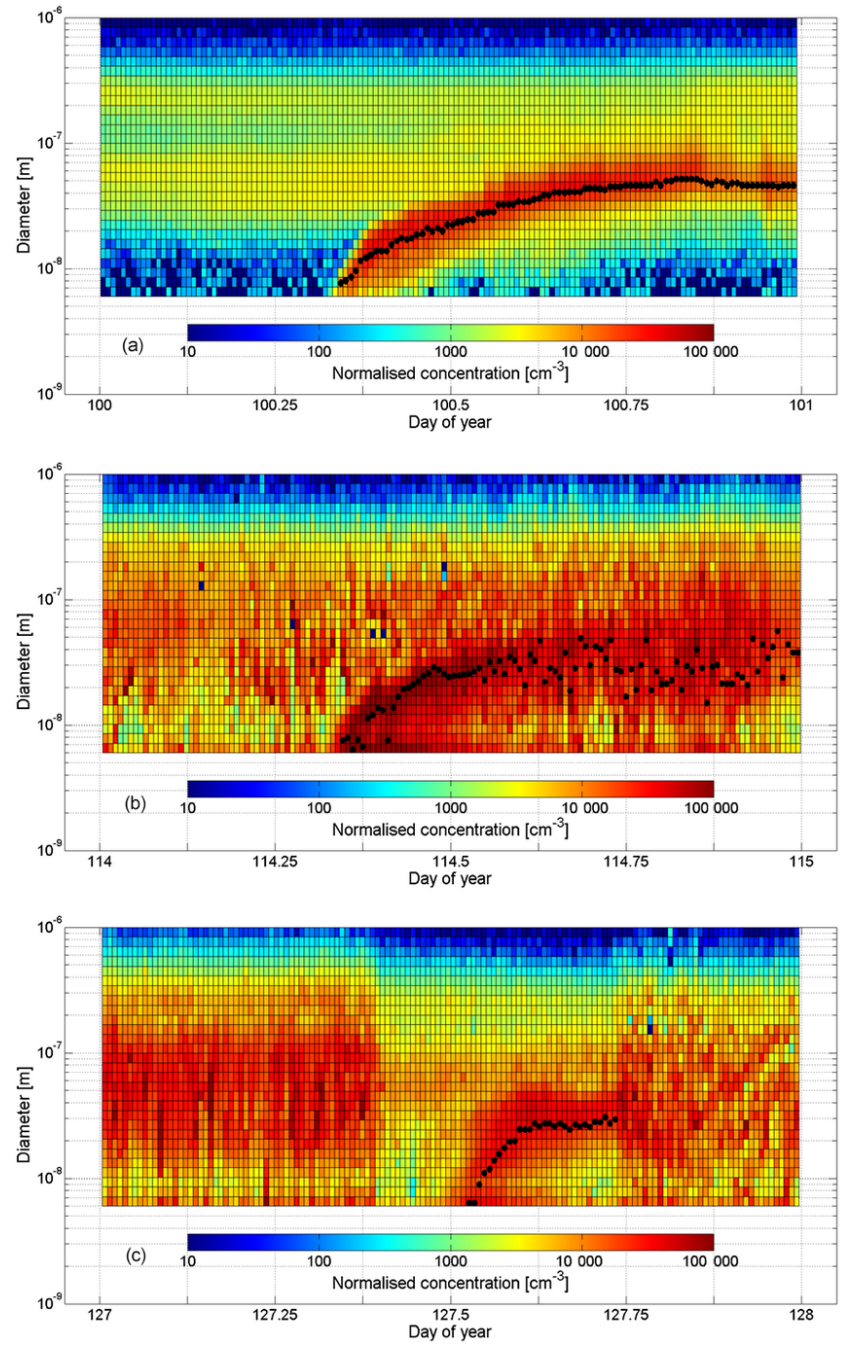

Figure 8. Banana-shaped size distribution surface plots for regional NPF and consecutive particle growth with narrow onset (a) in the near-city background on Monday, 9 April 2012, in a polluted urban air within the street canyon (b) on Sunday, 24 April 2011, and appearing at a certain time (c) in the street canyon on Saturday, 7 May 2011. Time series of the fitted particle number median mobility diameter for the nucleation mode are indicated by black dots on each panel.

evaporation from particles cannot be considered as realistic explanations. Changes in $\mathrm{O}_{3}$, GRad, Proxy, $\mathrm{RH}, T$ and partially WS are biased by their diurnal cycling or pattern, while the atmospheric concentrations are also influenced by PBL dynamics and mixing intensity (Hamed et al., 2011). The global radiation and gas-phase $\mathrm{H}_{2} \mathrm{SO}_{4}$ proxy showed the largest relative change when taking into account both the mean growth / shrinkage ratios and substantial change rates during the shrinkage phase. For these, there can be further relationships - in addition to the bias - between the variables and the physicochemical processes occurring within the particles during shrinkage. This can include decreased photo-
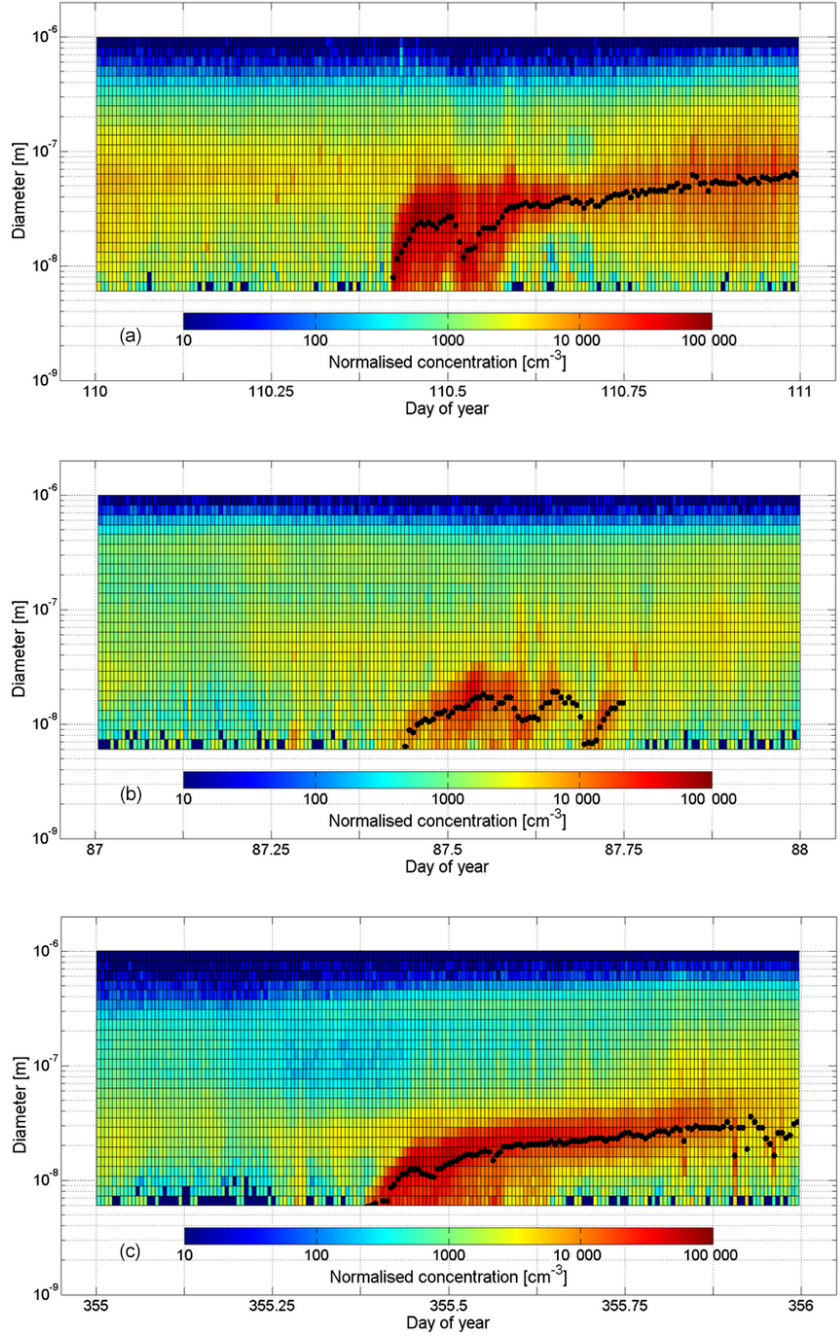

Figure 9. Size distribution surface plots for NPF and consecutive particle growth as banana-shaped plot with double onset (a) in the city centre on Sunday, 20 April 2014, with multiple onsets (b) in the city centre on Saturday, 28 March 2015, and with a broad continuous onset (c) in the city centre on Sunday, 21 December 2014. Time series of the fitted particle number median mobility diameter for the nucleation mode are indicated by black dots on each panel.

chemical activity or a decreased concentration of condensable chemical species, leading eventually to exhausted atmospheric supersaturation. The shrinkage could not, however, be fully explained by local atmospheric parameters. The relatively large time resolution ( $1 \mathrm{~h}$ ) of GRad in the present work, unfortunately, did not allow us to investigate the evaporation dynamics.

\section{Conclusions}

Chemical and physical conditions in urban atmospheric environments can be rather complex and variable both in space and time. They are also affected by the close surroundings, 

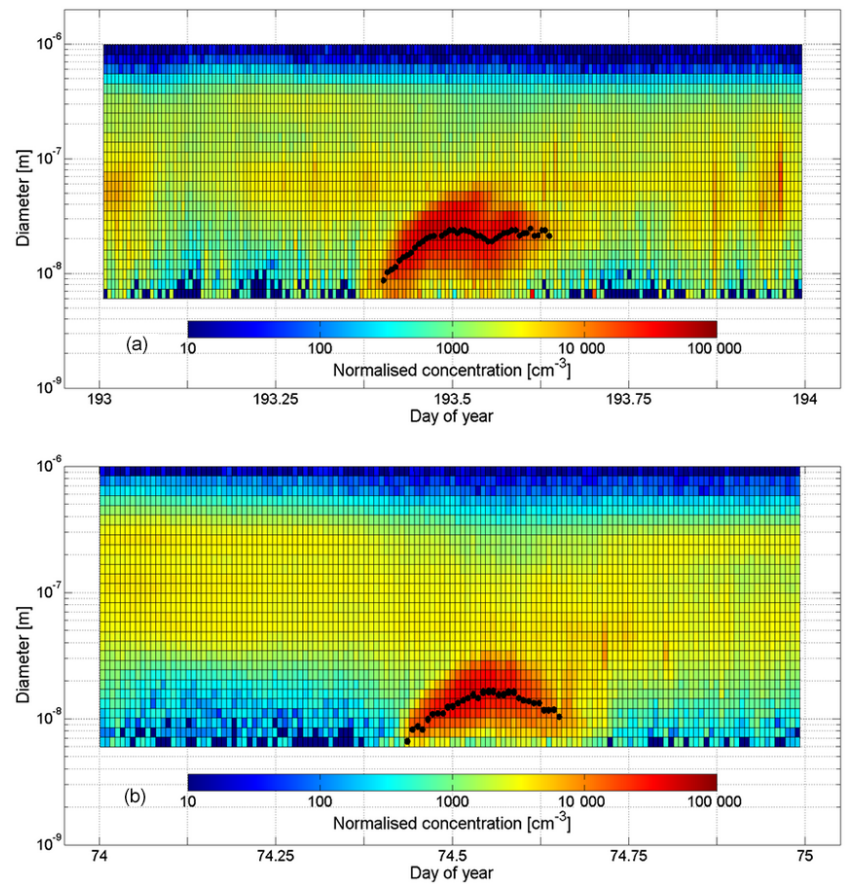

Figure 10. Size distribution surface plots for NPF and consecutive particle growth as banana-shaped plot limited in time (a) in the city centre on Tuesday, 12 July 2012, and as arch-shaped plot (b) in the city centre on Friday, 15 March 2013. Time series of the fitted particle number median mobility diameter for the nucleation mode are indicated by black dots on each panel.

constructions and orogeny. Long-term, continuous and representative measurements, which are the basis of contemporary aerosol studies, require a dedicated research infrastructure and devices. This also means that supplementary and interdisciplinary studies need to be performed at these measurement sites. Here we demonstrated a joint detailed study in atmospheric chemistry or physics, meteorology, and fluid dynamics for this purpose. The results and conclusion achieved represent a reliable background for later interpretations and conclusions. Various shapes of particle growth processes observed in 4-year-long measurements were presented and their classifications were discussed in detail. Misleading conclusions could be drawn if the actual activities around the measurement sites in cities, in particular in combination with transformation and other disturbance effects and fluctuating data were not considered. The particle diameter range $<10 \mathrm{~nm}$ of the measuring (DMPS) systems seems invaluable for correct and reliable NPF identification in urban environments. Arch-shaped surface plots provide information on freshly nucleated particles. Their shrinkage could be associated with the changes in local meteorology or atmospheric conditions, in particular decreased GRad and the gas-phase $\mathrm{H}_{2} \mathrm{SO}_{4}$ proxy (indirect $\mathrm{H}_{2} \mathrm{SO}_{4}$ concentration), and with air mixing. Considering that the mean contribution of $\mathrm{H}_{2} \mathrm{SO}_{4}$ condensation to the particle GR was estimated to
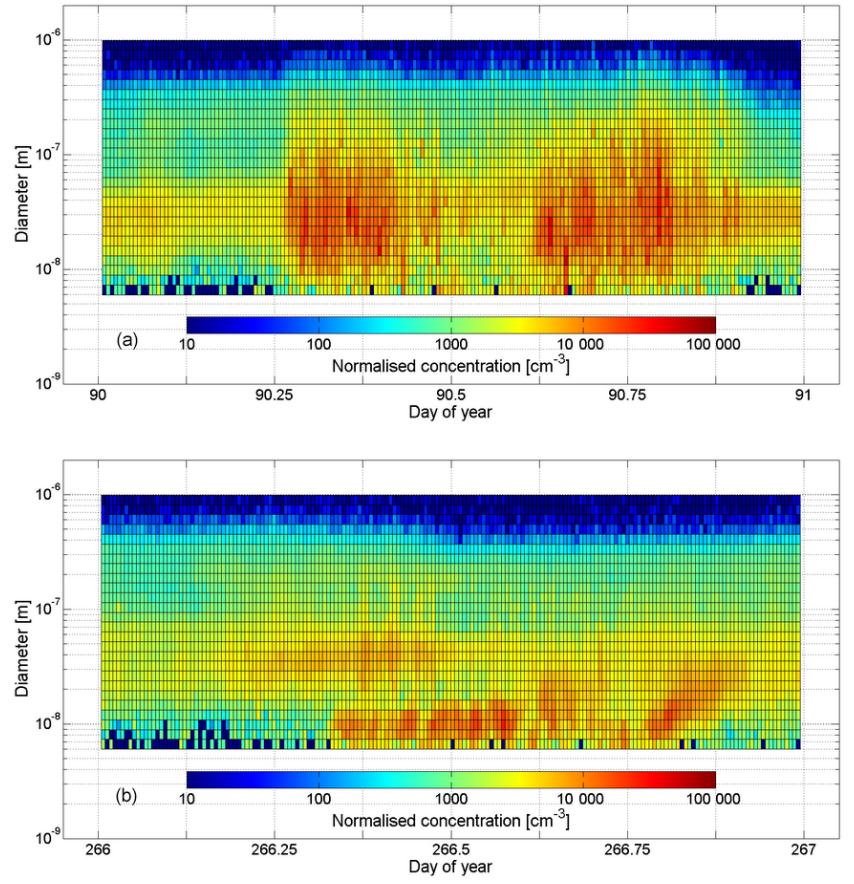

Figure 11. Size distribution surface plots showing the typical effects of vehicular road traffic emission sources and local meteorology (a) in the city centre on Tuesday, 31 March 2015, and of extensive grass cutting in the neighbourhood (b) of the BpART facility on Tuesday, 23 September 2014.

be $12.3 \%$ in Budapest (Salma et al., 2016), the explanation has to be extended by a concentration decrease in other condensable vapours, mainly organic compounds in general. The contribution of different chemical species to the particle growth varies with particle size as well. Non-volatile species are mainly responsible for the formation and initial growth, while the contribution of more volatile compounds increases with an increasing particle size (Zhang et al., 2004; Smith et al., 2008). This implies that both major ideas for the reasons for particle shrinkage (i.e. evaporation or variations in $J$ and GR during the atmospheric transport) could be accurate. Further insights into the shrinkage can be obtained in dedicated experiments on the evaporation dynamics, including aerosol mass spectrometry on the one hand and extended chemical transport modelling on the other hand.

\section{Data availability}

The relevant observational data used in this paper are available at http://salma.web.elte.hu/BpArt of the Eötvös University, Hungary, or on request from the corresponding author. 
Acknowledgements. Financial support by the Hungarian Scientific Research Fund (contracts K116788 and K108936) is appreciated. We are grateful to Regina Hitzenberger and Anna Wonaschütz, both of the University of Vienna, for providing the CPC2 for the intercomparison exercise and would like to thank Veronika Varga (Eötvös University) for her help in the data treatment of the intercomparison exercise and Mihály Vince (Budapest University of Technology and Economics) for his assistance in preparing the CFD modelling.

Edited by: V.-M. Kerminen

\section{References}

Alam, A., Shi, J. P., and Harrison, R. M.: Observation of new particle formation in urban air, J. Geophys. Res., 108, 4093-4107, 2003.

Asner, G. P., Scurlock, J. M. O., and Hicke, J. A.: Global synthesis of leaf area index observations: Implications for ecological and remote sensing studies, Global Ecol. Biogeogr., 12, 191-205, 2003.

Backman, J., Rizzo, L. V., Hakala, J., Nieminen, T., Manninen, H. E., Morais, F., Aalto, P. P., Siivola, E., Carbone, S., Hillamo, R., Artaxo, P., Virkkula, A., Petäjä, T., and Kulmala, M.: On the diurnal cycle of urban aerosols, black carbon and the occurrence of new particle formation events in springtime São Paulo, Brazil, Atmos. Chem. Phys., 12, 11733-11751, doi:10.5194/acp12-11733-2012, 2012.

Borsós, T., Řimnáčová, D., Ždímal, V., Smolík, J., Wagner, Z., Weidinger, T., Burkart, J., Steiner, G., Reischl, G., Hitzenberger, R., Schwarz, J., and Salma, I.: Comparison of particulate number concentrations in three Central European capital cities, Sci. Total Environ., 433, 418-426, 2012.

Braakhuis, H. M., Park, M. V., Gosens, I., De Jong, W. H., and Cassee, F. R.: Physicochemical characteristics of nanomaterials that affect pulmonary inflammation, Part. Fibre. Toxicol., 11, 18, doi:10.1186/1743-8977-11-18, 2014.

Bzdek, B. R., Zordan, C. A., Pennington, M. R., Luther III, G. W., and Johnston, M. V.: Quantitative assessment of the sulfuric acid contribution to new particle growth, Environ. Sci. Technol., 46, 4365-4373, 2012.

Cusack, M., Alastuey, A., and Querol, X.: Case studies of new particle formation and evaporation processes in the Western Mediterranean regional background, Atmos. Environ., 81, 651659,2013

Dall'Osto, M., Querol, X., Alastuey, A., O’Dowd, C., Harrison, R. M., Wenger, J., and Gómez-Moreno, F. J.: On the spatial distribution and evolution of ultrafine particles in Barcelona, Atmos. Chem. Phys., 13, 741-759, doi:10.5194/acp-13-741-2013, 2013.

Dal Maso, M., Kulmala, M., Riipinen, I., Wagner, R., Hussein, T., Aalto, P. P., and Lehtinen, K. E. J.: Formation and growth of fresh atmospheric aerosols: eight years of aerosol size distribution data from SMEAR II, Hyytiälä, Finland, Boreal Environ. Res., 10, 323-336, 2005.

Ehn, M., Thornton, J. A., Kleist, E., Sipila, M., Junninen, H., Pullinen, I., Springer, M., Rubach, F., Tillmann, R., Lee, B., LopezHilfiker, F., Andres, S., Acir, I. H., Rissanen, M., Jokinen, T., Schobesberger, S., Kangasluoma, J., Kontkanen, J., Nieminen,
T., Kurten, T., Nielsen, L. B., Jorgensen, S., Kjaergaard, H. G., Canagaratna, M., Dal Maso, M., Berndt, T., Petaja, T., Wahner, A., Kerminen, V. M., Kulmala, M., Worsnop, D. R., Wildt, J., and Mentel, T. F.: A large source of low-volatility secondary organic aerosol, Nature, 506, 476-479, 2014.

Hamed, A., Korhonen, H., Sihto, S. L., Joutsensaari, J., Järvinen, H., Petäjä, T., Arnold, F., Nieminen, T., Kulmala, M., Smith, J. S., Lehtinen, K. E. J., and Laaksonen, A.: The role of relative humidity in continental new particle formation, J. Geophys. Res., 116, D03202, doi:10.1029/2010JD014186, 2011.

Hermann, M., Wehner, B., Bischof, O. F., Han, H.-S., Krinke, T. J., Liu, W., Zerrath, A. F., and Wiedensohler, A.: Particle counting efficiencies of new TSI condensation particle counters, J. Aerosol Sci., 38, 674-682, 2007.

Hirsikko, A., Vakkari, V., Tiitta, P., Hatakka, J., Kerminen, V.-M., Sundström, A.-M., Beukes, J. P., Manninen, H. E., Kulmala, M., and Laakso, L.: Multiple daytime nucleation events in semi-clean savannah and industrial environments in South Africa: analysis based on observations, Atmos. Chem. Phys., 13, 5523-5532, doi:10.5194/acp-13-5523-2013, 2013.

Hussein, T., Puustinen, A., Aalto, P. P., Mäkelä, J. M., Hämeri, K., and Kulmala, M.: Urban aerosol number size distributions, Atmos. Chem. Phys., 4, 391-411, doi:10.5194/acp-4-391-2004, 2004.

Kerminen, V.-M., Paramonov, M., Anttila, T., Riipinen, I., Fountoukis, C., Korhonen, H., Asmi, E., Laakso, L., Lihavainen, H., Swietlicki, E., Svenningsson, B., Asmi, A., Pandis, S. N., Kulmala, M., and Petäjä, T.: Cloud condensation nuclei production associated with atmospheric nucleation: a synthesis based on existing literature and new results, Atmos. Chem. Phys., 12, 1203712059, doi:10.5194/acp-12-12037-2012, 2012.

Kivekäs, N., Carpman, J., Roldin, P., Leppä, J., O'Connor, E., Kristensson, A., and Asmi, E.: Coupling an aerosol box model with one-dimensional flow: a tool for understanding observations of new particle formation events, Tellus B, 68, 29706 , doi:10.3402/tellusb.v68.29706, 2016.

Kulmala, M., Petäjä, T., Mönkkönen, P., Koponen, I. K., Dal Maso, M., Aalto, P. P., Lehtinen, K. E. J., and Kerminen, V.-M.: On the growth of nucleation mode particles: source rates of condensable vapor in polluted and clean environments, Atmos. Chem. Phys., 5, 409-416, doi:10.5194/acp-5-409-2005, 2005.

Kulmala, M., Petäjä, T., Nieminen, T., Sipilä, M., Manninen, H. E., Lehtipalo, K., Dal Maso, M., Aalto, P. P., Junninen, H., and Paasonen, P.: Measurement of the nucleation of atmospheric aerosol particles, Nat. Protoc., 7, 1651-1667, 2012.

Kulmala, M., Kontkanen, J., Junninen, H., Lehtipalo, K., Manninen, H. E., Nieminen, T., Petäjä, T., Sipilä, M., Schobesberger, S., Rantala, P., Franchin, A., Jokinen, T., Järvinen, E., Äijälä, M., Kangasluoma, J., Hakala, J., Aalto, P. P., Paasonen, P., Mikkilä, J., Vanhanen, J., Aalto, J., Hakola, H., Makkonen, U., Ruuskanen, T., Mauldin III, R. L., Duplissy, J., Vehkamäki, H., Bäck, J., Kortelainen, A., Riipinen, I., Kurtén, T., Johnston, M. V., Smith, J. N., Ehn, M., Mentel, T. F., Lehtinen, K. E. J., Laaksonen, A., Kerminen, V.-M., and Worsnop, D. R.: Direct observations of atmospheric aerosol nucleation, Science, 339, 943-946, 2013.

Merikanto, J., Spracklen, D. V., Mann, G. W., Pickering, S. J., and Carslaw, K. S.: Impact of nucleation on global CCN, Atmos. Chem. Phys., 9, 8601-8616, doi:10.5194/acp-9-8601-2009, 2009. 
Morawska, L., Ristovski, Z., Jayaratne, E. R., Keogh, D. U., and Ling, X.: Ambient nano and ultrafine particles from motor vehicle emissions: Characteristics, ambient processing and implications on human exposure, Atmos. Environ., 42, 8113-8138, 2008.

Németh, Z. and Salma, I.: Spatial extension of nucleating air masses in the Carpathian Basin, Atmos. Chem. Phys., 14, 8841-8848, doi:10.5194/acp-14-8841-2014, 2014.

Németh, Z., Pósfai, M., Nyirő-Kósa, I., Aalto, P., Kulmala, M., and Salma, I.: Images and properties of individual nucleated particles, Atmos. Environ., 123, 166-170, 2015.

Oberdörster, G., Oberdörster, E., and Oberdörster, J.: Nanotoxicology: an emerging discipline evolving from studies of ultrafine particles, Environ. Health Perspect., 113, 823-839, 2005.

Operation and Service Manual: Model 3775 Condensation Particle Counter, Revision D, TSI Inc., Shoreview, USA, 2007.

Petäjä, T., Mauldin, III, R. L., Kosciuch, E., McGrath, J., Nieminen, T., Paasonen, P., Boy, M., Adamov, A., Kotiaho, T., and Kulmala, M.: Sulfuric acid and $\mathrm{OH}$ concentrations in a boreal forest site, Atmos. Chem. Phys., 9, 7435-7448, doi:10.5194/acp9-7435-2009, 2009.

Salma, I., Maenhaut, W., Zemplén-Papp, É., and Záray, Gy.: Comprehensive characterisation of atmospheric aerosols in Budapest, Hungary: physicochemical properties of inorganic species, Atmos. Environ., 35, 4367-4378, 2001.

Salma, I., Borsós, T., Weidinger, T., Aalto, P., Hussein, T., Dal Maso, M., and Kulmala, M.: Production, growth and properties of ultrafine atmospheric aerosol particles in an urban environment, Atmos. Chem. Phys., 11, 1339-1353, doi:10.5194/acp-111339-2011, 2011a.

Salma, I., Borsós, T., Aalto, P. P., and Kulmala, M.: Time-resolved number concentration and size distribution of aerosol particles in an urban road tunnel, Boreal Environ. Res., 16, 262-272, 2011 b.

Salma, I., Borsós, T., Németh, Z., Weidinger, T., Aalto, T., and Kulmala, M.: Comparative study of ultrafine atmospheric aerosol within a city, Atmos. Environ., 92, 154-161, 2014.

Salma, I., Füri, P., Németh, Z., Farkas, Á., Balásházy, I., Hofmann, W., and Farkas, Á.: Lung burden and deposition distribution of inhaled atmospheric urban ultrafine particles as the first step in their health risk assessment, Atmos. Environ., 104, 39-49, 2015.

Salma, I., Németh, Z., Kerminen, V.-M., Aalto, P., Nieminen, T., Weidinger, T., Molnár, Á., Imre, K., and Kulmala, M.: Regional effect on urban atmospheric nucleation, Atmos. Chem. Phys. Discuss., doi:10.5194/acp-2016-115, in review, 2016.

Skrabalova, L., Zikova, N., and Zdimal, V.: Shrinkage of newly formed particles in an urban environment, Aerosol Air Qual. Res., 15, 1313-1324, 2015.

Smith, J. N., Dunn, M. J., VanReken, T. M., Iida, K., Stolzenburg, M. R., McMurry, P. H., and Huey, P. H.: Chemical composition of atmospheric nanoparticles formed from nucleation in Tecamac, Mexico: Evidence for an important role for organic species in nanoparticle growth, Geophys. Res. Lett., 35, L04808, doi:10.1029/2007GL032523, 2008.
Wehner, B., Wiedensohler, A., Tuch, T. M., Wu, Z. J., Hu, M., Slanina, J., and Kiang, C. S: Variability of the aerosol number size distribution in Beijing, China: new particle formation, dust storms, and high continental background, Geophys. Res. Lett., 31, L22108, doi:10.1029/2004GL021596, 2004.

Weidinger, T., Nagy, Z., Baranka, Gy., Mészáros, R., and Gyöngyösi, A. Z.: Determination of meteorological preprocessor for air quality models in the New Hungarian Standards, Croat. Meteorol. J., 12, 460-464, 2008.

Wiedensohler, A., Birmili, W., Nowak, A., Sonntag, A., Weinhold, K., Merkel, M., Wehner, B., Tuch, T., Pfeifer, S., Fiebig, M., Fjäraa, A. M., Asmi, E., Sellegri, K., Depuy, R., Venzac, H., Villani, P., Laj, P., Aalto, P., Ogren, J. A., Swietlicki, E., Williams, P., Roldin, P., Quincey, P., Hüglin, C., Fierz-Schmidhauser, R., Gysel, M., Weingartner, E., Riccobono, F., Santos, S., Grüning, C., Faloon, K., Beddows, D., Harrison, R., Monahan, C., Jennings, S. G., O’Dowd, C. D., Marinoni, A., Horn, H.-G., Keck, L., Jiang, J., Scheckman, J., McMurry, P. H., Deng, Z., Zhao, C. S., Moerman, M., Henzing, B., de Leeuw, G., Löschau, G., and Bastian, S.: Mobility particle size spectrometers: harmonization of technical standards and data structure to facilitate high quality long-term observations of atmospheric particle number size distributions, Atmos. Meas. Tech., 5, 657-685, doi:10.5194/amt5-657-2012, 2012

Xiao, S., Wang, M. Y., Yao, L., Kulmala, M., Zhou, B., Yang, X., Chen, J. M., Wang, D. F., Fu, Q. Y., Worsnop, D. R., and Wang, L.: Strong atmospheric new particle formation in winter in urban Shanghai, China, Atmos. Chem. Phys., 15, 1769-1781, doi:10.5194/acp-15-1769-2015, 2015.

Yao, X., Choi, M. Y., Lau, N. T., Lau, A. P. S., Chan, C. K., and Fang, M.: Growth and shrinkage of new particles in the atmosphere in Hong Kong, Aerosol Sci. Tech., 44, 639-650, 2010.

Yli-Juuti, T., Riipinen, I., Aalto, P. P., Nieminen, T., Maenhaut, W., Janssens, I. A., Claeys, M., Salma, I., Ocskay, R., Hoffer, A., Imre, K., and Kulmala, M.: Characteristics of new particle formation events and cluster ions at K-puszta, Hungary, Boreal Environ. Res., 14, 683-698, 2009.

Young, L.-H., Lee, S.-H., Kanawade, V. P., Hsiao, T.-C., Lee, Y. L., Hwang, B.-F., Liou, Y.-J., Hsu, H.-T., and Tsai, P.-J.: New particle growth and shrinkage observed in subtropical environments, Atmos. Chem. Phys., 13, 547-564, doi:10.5194/acp-13547-2013, 2013.

Zhang, R., Suh, I., Zhao, J., Zhang, D., Fortner, E. C., Tie, X., Molina, L. T., and Molina, M. J.: Atmospheric new particle formation enhanced by organic acids, Science, 304, 1487-1490, 2004. 